\title{
An ectopic intramedullary hematopoietic niche in a cervical spine meniscoid: a case report
}

\author{
Vascular Cell 9:1 | DOI: 10.24238/13221-9-1-173 | C Li et al.; licensee Publiverse Online S.R.L. 2017 \\ Received: 20 Jul 2017 | Accepted: 11 Dec 2017 | Published: 15 Dec 2017 \\ Farrell Scott F. ${ }^{@}$, Petcu Eugen B., Cornwall Jon, Rivett Darren A., Osmotherly Peter G. \\ ${ }^{+}$Contributed equally ${ }^{@}$ Corresponding author
}

\begin{abstract}
We present the first documented case of an ectopic intramedullary hematopoietic niche within a cervical zygapophyseal joint intra-articular meniscoid. The meniscoid was identified in the cervical spine of an 81-year-old male cadaver, located at the dorsal aspect of the right C4-5 zygapophyseal joint, and was noted to be larger and more dense than other meniscoids during disarticulation and dissection of the joint. Histologically, the meniscoid contained hematopoietic cells surrounded by lamellar bone, and was lined with articular cartilage on the surface protruding into the joint cavity. Radiologically, the structure was hypointense on both T1- and T2-weighted magnetic resonance imaging sequences. The potential mechanisms underpinning development of this novel finding and the possible clinical implications are discussed in this report.
\end{abstract}

\section{Keywords}

hematopoiesis - zygapophyseal joint - synovial membrane - ossification - heterotopic - cervical vertebrae - joint diseases

\section{Introduction}

Hematopoesis refers to the production and maturation of blood cells, which occurs in bone marrow in intratrabecular spaces within bone medullary cavities [ 1]. Histological evidence suggests that this process can also occur within trabecular bone of tissue affected by heterotopic ossification, such as secondary to combat trauma [2] and following surgery [ 3]. The term 'ectopic intramedullary hematopoiesis' was coined by Davis and colleagues [2] to describe this phenomenon and distinguish it from extramedullary hematopoiesis, as in such cases, hematopoiesis occurs within heterotopic ossification, and is therefore not explicitly extramedullary.

Physiological processes affecting the cervical spine meniscoids, folds of synovium located within the zygapophyseal joints, has become increasingly relevant to basic scientists and clinicians as their potential contribution to spinal pain has become better understood [ 4- 7]. Cervical zygapophyseal joint meniscoids are visible on magnetic resonance imaging (MRI) and pathology involving these structures is a potential differential diagnosis for neck pain [4]. We present here the first documented case of an ectopic intramedullary hematopoietic niche within heterotopic ossification of a cervical zygapophyseal joint intra-articular meniscoid.

\section{Case Report}

The cervical spine of a cadaver (male, 81 years of age at death) was dissected as part of a radiologic and histologic study of zygapophyseal joint morphology. The donor had bequeathed his body to a medical school anatomy department in accordance with relevant legislation, and the study was granted institutional human research ethics approval. Medical records indicate the donor died from metastatic prostate cancer, and had undergone C5-6 fusion with bone grafting after a vertebral fracture approximately 50 years premortem. Prior to dissection, the head and neck were removed and underwent MRI with T1- and T2-weighted sequences in the sagittal plane (3-Telsa Magnetom Skyra, Siemens AG, Munich, Germany). During dissection, a meniscoid of unusual appearance was identified at the dorsal aspect of the right C4-5 zygapophyseal joint after disarticulation; the meniscoid was larger and firmer than previously observed specimens. The meniscoid was excised, embedded in paraffin, with sections $(4 \mu \mathrm{m})$ subsequently slide mounted and processed using hematoxylin and eosin. Histopathological evaluation revealed lymphoplasmacytic cellular population admixed with erythroid cells, granulocytes, megakaryocytes and macrophages surrounded by lamellar bone [ 8]. The dorsal aspect of the meniscoid adjoined the fibrous tissue of the joint capsule, and the ventral surface - the surface projecting into the joint cavity - was lined with articular cartilage (Fig. 1a, 1b). MRI revealed the structure was hypointense on both T1- and T2- 
Figure 1. Histologic and MRI Characteristics of Ossified Spinal Meniscoid
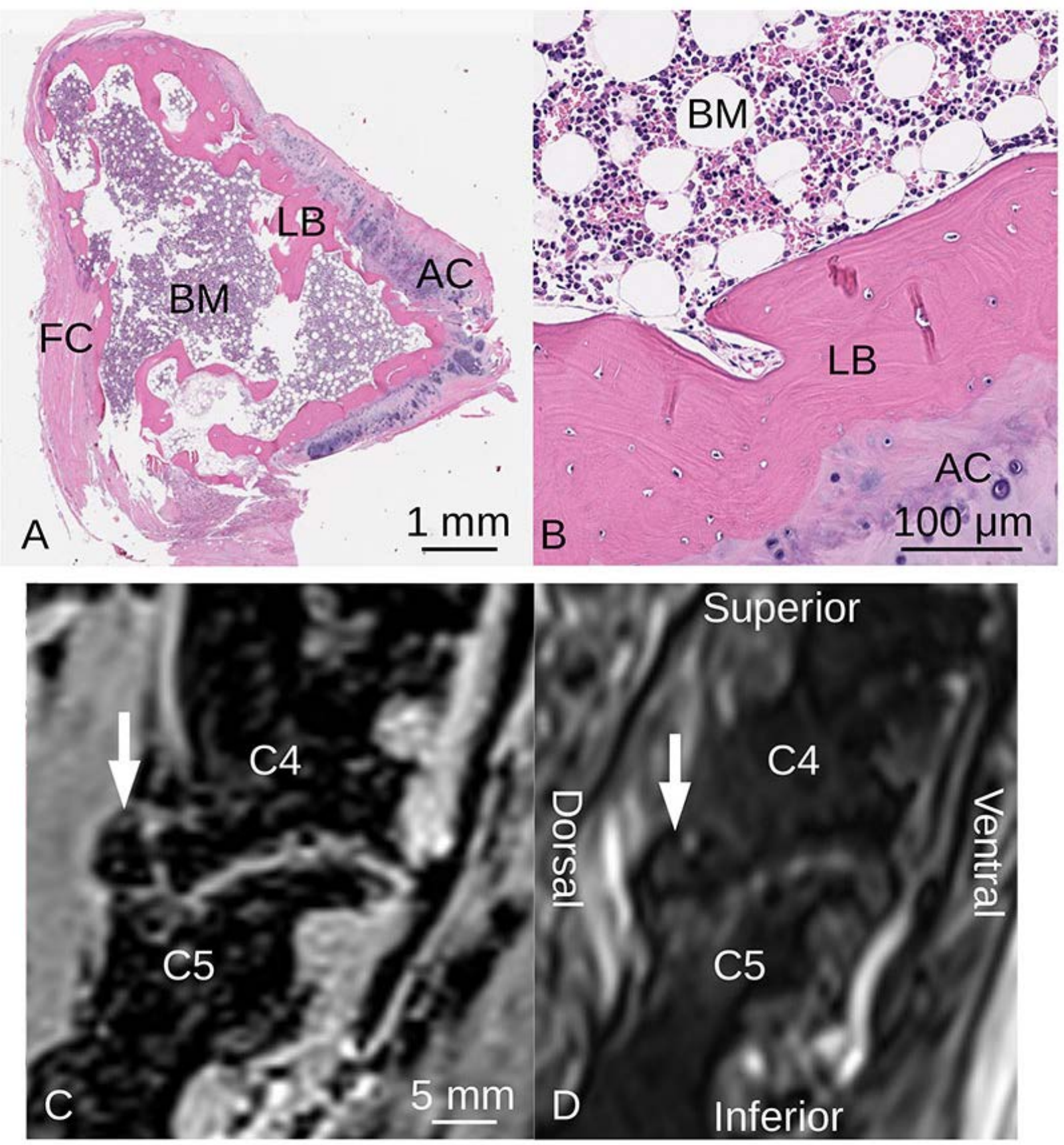

(A, B) Sagittal section of right C4-5 zygapophyseal joint intra-articular meniscoid photographed through a light microscope, illustrating articular cartilage, lamellar bone and bone marrow (hematopoietic cells, adipose cells) (hematoxylin and eosin). AC: articular cartilage, BM: bone marrow, FC: fibrous capsule, LB: lamellar bone. Sagittal cervical spine MRI of right C4-5 zygapophyseal joint using (C) T1-weighted VIBE and (D) T2-weighted SPACE sequences. The ossified meniscoid (white arrows) is hypointense on both imaging sequences.

\section{Discussion}

The histologic and radiologic findings of the present case support the hypothesis that the dorsal meniscoid of the right C4-5 zygapophyseal joint has undergone heterotopic ossification, forming an ectopic intramedullary hematopoietic niche. Heterotopic ossification refers to the formation of lamellar bone in soft tissue, and is acknowledged as a complication that may follow musculoskeletal trauma, surgery or central nervous system injury [ $2,3,9]$. Following such an initiating event, the pathophysiological mechanisms underpinning heterotopic ossification are thought to comprise multiple factors as described by McCarthy and Sundaram [10]: a signal is generated at the site of injury, possibly a bone morphogenetic protein secreted by cells of the injured tissue, or from inflammatory cells accumulating at the site of injury. Next, 
mesenchymal cells must be present and capable of differentiating into osteoblasts or chondroblasts. Finally, an environment with appropriate conditions for the production and maintenance of bone is required. Approaches to management of heterotopic ossification range from simple observation, to radiotherapy [11], to surgical excision and subsequent physical therapy; clinical decision-making is typically based upon patient symptoms and the impact of the ossification upon patient mobility and function [9].

It is theorised that an ectopic intramedullary hematopoietic niche may form in heterotopic ossification as a compensatory mechanism to address unmet hematopoietic needs in chronic anaemia, such as that related to hematologic diseases or limb amputation $[2,3]$. We suggest that in the present case, meniscoid ossification may have occurred secondary to the spinal fracture and subsequent surgery. Since the patient had metastatic cancer, we could speculate that the ectopic intramedullary hematopoietic niche may represent the final response to chronic anaemia, related to chemotherapy for metastatic cancer [ $12]$.

Prior reports of cervical zygapophyseal joint meniscoid morphology indicate that these structures are composed of adipose tissue and/or fibrous tissue, lined with synovial membrane [ 13, 14]. Anomalies in the anatomy of these structures are not frequently reported. In an autopsy study of the zygapophyseal joints of 40 people, Uhrenholt and colleagues [15] observed a small number of meniscoids which spanned the entire ventral-dorsal length of their enclosing joints on parasagittal histological sections. Similarly, Khan and Farrell [ 16] have reported anatomical variation in the lateral atlantoaxial joint meniscoids of an asymptomatic 57-year-old female in vivo using MRI, in which both left and right joints did not have ventral meniscoids, but instead each contained a large dorsal meniscoid that spanned the complete dorsal-ventral lengths of their respective joint cavities. However, none of the previously published reports mention active hematopoiesis and heterotopic ossification of a cervical spine meniscoid has not previously been reported.

This novel case demonstrates that cervical spine meniscoids can undergo heterotopic ossification. The insight advances current appreciation of patterns of variation in meniscoid anatomy, and has potential implications for the diagnosis and management of cervical spine pathology. Our report indicates that if present, heterotopic ossification with intramedullary hematopoiesis may impact upon zygapophyseal joint motion, and in turn cervical spine function, as ossified meniscoids could provide a mechanical obstruction to joint motion. Awareness of this pathology is of relevance to clinicians managing patients after spinal surgery or trauma - conditions known to be associated with the development of heterotopic ossification. Therefore, this pathoanatomical entity should be considered as a potential differential diagnosis during assessment of cervical spine pathology when such history is present. Further research is required to investigate the clinical implications of cervical zygapophyseal joint meniscoid heterotopic ossification, refine diagnostic criteria for this pathology, and evaluate approaches to patient management of heterotopic ossification of these structures.

\section{Declarations}

\section{Ethics statement}

This study received institutional research ethics approval from The University of Queensland Human Research Ethics Committee (ref H-2015-0096).

\section{Conflicts of interest and sources of funding statement}

The authors state that there are no conflicts of interest or sources of funding to disclose.

\section{References}

1. Cumano A., Godin I.. Ontogeny of the Hematopoietic System. Annual Review of Immunology. 2007;25:745785 .

View Article Google Scholar

2. Davis T. A., Lazdun Y., Potter B. K., Forsberg J. A.. Ectopic bone formation in severely combat-injured orthopedic patients - a hematopoietic niche. Bone. 2013;56:119-126.

View Article Google Scholar

3. Wang D., Shurafa M. S., Acharya R., Strand V. F., Linden M. D.. Chronic abdominal pain caused by heterotopic ossification with functioning bone marrow. Archives of Pathology \& Laboratory Medicine. 2004;128:321-323.

View Article Google Scholar

4. Webb A. L., Collins P., Rassoulian H., Mitchell B. S.. Synovial folds - A pain in the neck?. Manual Therapy. 2011;16:118-124. 
5. Farrell S. F., Osmotherly P. G., Cornwall J., Rivett D. A.. Immunohistochemical investigation of nerve fibre presence and morphology in elderly cervical spine meniscoids. The Spine Journal. 2016;16 (10):1244-1252. View Article Google Scholar

6. Farrell S. F., Osmotherly P. G., Cornwall J., Sterling M., Rivett D. A.. Cervical spine meniscoids: an update on their morphological characteristics and potential clinical significance. Eur Spine J. 2017;26 (4):939-947.

View Article Google Scholar

7. Farrell S. F., Khan S., Osmotherly P. G., Sterling M., Cornwall J., Rivett D. A.. Lateral atlantoaxial joint meniscoid volume in individuals with whiplash associated disorder: a case-control study. Musculoskeletal Science and Practice. 2018;33:46-52.

View Article Google Scholar

8. Kerr J. B.. Blood. Functional Histology. 2nd edn. Mosby, Sydney. 2010;:--

View Article Google Scholar

9. Barfield W. R., Holmes R. E., Hartsock L. A.. Heterotopic Ossification in Trauma. Orthopedic Clinics of North America. 2017;48:35-46.

View Article Google Scholar

10. McCarthy E. F., Sundaram M.. Heterotopic ossification: a review. Skeletal Radiology. 2005;34:609-619. View Article Google Scholar

11. Mattei T. A., Higgins M., Joseph F., Mendel E.. Ectopic extramedullary hematopoiesis: evaluation and treatment of a rare and benign paraspinal/epidural tumor. Journal of Neurosurgery: Spine. 2013;18 (3):236242 .

View Article Google Scholar

12. Ludwig H., Wedding U., Van Belle S.. Anaemia in elderly patients with cancer: Focus on chemotherapyinduced anaemia. Journal of Geriatric Oncology. 2012;3:256-264.

View Article Google Scholar

13. Inami S., Kaneoka K., Hayashi K., Ochiai N.. Types of synovial fold in the cervical facet joint. Journal of Orthopaedic Science. 2000;5:475-480.

View Article Google Scholar

14. Farrell S. F., Osmotherly P. G., Cornwall J., Rivett D. A.. The anatomy and morphometry of cervical zygapophyseal joint meniscoids. Surg Radiol Anat. 2015;37 (7):799-807.

View Article Google Scholar

15. Uhrenholt L., Hauge E., Vesterby Charles B., Gregersen M.. Degenerative and traumatic changes in the lower cervical spine facet joints. Scandinavian Journal of Rheumatology. 2008;37:375-384.

View Article Google Scholar

16. Khan S., Farrell S. F.. A unique bilateral variation of lateral atlantoaxial joint meniscoid morphology: case report. Anatomy. 2016;10 (2):153-155.

View Article Google Scholar 